3

\title{
Geographic Disparities and Predictors of COVID-19 Hospitalization Risk in the St. Louis Area, Missouri (USA).
}

Morganne Igoe ${ }^{1}$, Praachi Das ${ }^{2}$, Suzanne Lenhart ${ }^{1}$, Alun L. Lloyd ${ }^{2}$, Lan Luong ${ }^{3}$, Dajun Tian $^{3}$, Cristina Lanzas ${ }^{4}$, Agricola Odoi ${ }^{5, \S}$

${ }^{1}$ Department of Mathematics, University of Tennessee, Knoxville, 37996

${ }^{2}$ Biomathematics Graduate Program and Department of Mathematics, North Carolina State University, Raleigh NC 27695

${ }^{3}$ BJC Healthcare, St. Louis, Missouri, 63110

${ }^{4}$ Department of Population Health and Pathobiology and Comparative Medicine Institute, North Carolina State University, Raleigh, 27607

${ }^{5}$ Department of Biomedical and Diagnostics Sciences, University of Tennessee, Knoxville, 37996

\section{\$Corresponding Author:}

Agricola Odoi, aodoi@utk.edu 


\section{Abstract}

43 Background: COVID-19 has overwhelmed the US healthcare system, with over 44

44 million cases and over 700,000 deaths as of October 6,2021 . There is evidence that

45 some communities are disproportionately affected. This may result in geographic

46 disparities in COVID-19 hospitalization risk that, if identified, could guide control efforts.

47 Therefore, the objective of this study is to investigate Zip Code Tabulation Area (ZCTA)-

48 level geographic disparities and identify predictors of COVID-19 hospitalization risk in

49 the St. Louis area.

50 Methods: Hospitalization data for COVID-19 and several chronic diseases were

51 obtained from the Missouri Hospital Association. ZCTA-level data on socioeconomic

52 and demographic factors were obtained from the US Census Bureau American

53 Community Survey. Age-adjusted COVID-19 and several chronic disease

54 hospitalization risks were calculated. Geographic disparities in distribution of COVID-19

55 age-adjusted hospitalization risk, socioeconomic and demographic factors as well as

56 chronic disease risks were investigated using choropleth maps. Predictors of ZCTA-

57 level COVID-19 hospitalization risks were investigated using global negative binomial

58 and local geographically weighted negative binomial models.

59 Results: There were geographic disparities of COVID-19 hospitalization risks. COVID-

6019 hospitalization risks were significantly higher in ZCTAs with high diabetes

61 hospitalization risks ( $p<0.0001)$, high risks of COVID-19 cases $(p<0.0001)$, as well as

62 high percentages of black population $(p=0.0416)$ and populations with some college

63 education $(p=0.0005)$. The coefficients of the first three predictors varied across ZCTAs,

64 implying that the associations between COVID-19 hospitalization risks and these 
65 predictors varied by geographic location. This implies that a "one-size-fits-all" approach

66 may not be appropriate for management and control.

67 Conclusions: There is evidence of geographic disparities in COVID-19 hospitalization

68 risks that are driven by differences in socioeconomic, demographic and health-related

69 factors. The impacts of these factors vary by geographical location with some factors

70 being more important predictors in some locales than others. Use of both global and

71 local models leads to a better understanding of the determinants of geographic

72 disparities in health outcomes and utilization of health services. These findings are

73 useful for informing health planning to identify geographic areas likely to have high

74 numbers of individuals needing hospitalization as well as guiding vaccination efforts.

81 Key Words: Severe Acute Respiratory Syndrome Coronavirus 2; SARS-CoV-2; Coronavirus

82 Disease 2019; COVID-19; Disparities; Hospitalization Risks; Predictors; Negative Binomial

83 Models; Geographically Weighted Regression Models; Epidemiology; Missouri. 


\section{Background}

85 There have been over 184 million confirmed Coronavirus Disease 2019 (COVID-19)

86 cases and over 4 million deaths worldwide as of July 8, 2021, with over 33 million

87 confirmed cases and over 600,000 deaths in the United States [1]. As of the same date,

88 the state of Missouri has reported over 633,000 cases and 9,700+ deaths. The disease

89 has overwhelmed many United States hospital systems, with large numbers of patients

90 requiring critical care and interventions such as mechanical ventilation [2-4]. This surge

91 of COVID-19 patients has put strain on hospital resources, potentially impacting the

92 care available to both COVID-19 and non-COVID-19 patients [5].

94 There is evidence of geographic disparities in the severity of the disease with certain

95 population groups experiencing more severe disease than others. These disparities

96 might be driven by population characteristics such as socioeconomic, demographic, and

97 chronic disease factors [6-10]. For instance, there is evidence that Non-Hispanic

98 American Indian, non-Hispanic Black, and Hispanic people have higher hospitalization

99 risks than their non-Hispanic Asian and non-Hispanic White counterparts [11].There are

100 also reports that conditions such as diabetes mellitus, obesity, chronic lung conditions,

101 renal disease, cancer, and cardiovascular disease may increase the severity of the

102 condition and risk of hospitalizations among COVID-19 patients with these co-

103 morbidities [6, 12-14]. Identifying geographic disparities in COVID-19 hospitalization

104 risks and determinants of these disparities is important in providing information to guide

105 hospital preparedness to handle the patient surge and for targeting resources for public

106 health efforts to control the condition at the community level. 
108 Improved understanding of the geographic disparities and predictors of COVID-19

109 hospitalization risk at the local level, such as the Zip Code Tabulation Areas (ZCTA),

110 would help identify local geographic areas with higher needs for hospital beds and other

111 healthcare resources. This is useful information for healthcare planning and service

112 provision at the local level. It may also inform vaccination efforts by helping to identify

113 areas where higher vaccination coverage may have the largest effect in reducing

114 hospital burden. Therefore, the objective of this study is to identify geographic

115 disparities and predictors of COVID-19 hospitalization risk in the St. Louis Area,

116 Missouri, United States. 


\section{Methods}

\section{Study Area}

119 This study was performed in an area of Missouri that includes 108 ZCTAs located in St.

120 Charles county, St. Louis county, and St. Louis City as well as parts of Jefferson,

121 Franklin and Warren counties (Figure 1). The area had a population of approximately 2

122 million people comprising 74\% white, 20\% black, 3\% Hispanic/Latino, and 3\% Asian.

123 Forty-eight percent of the population was male, while $52 \%$ was female. Thirty-one

124 percent of the population was older than 25 years old, $53 \%$ was $25-64$, and $16 \%$ was

125 older than 65 years of age. The ZCTA-level population density varied from 10 people

126 per square mile in St. Charles County to 9,368 people per square mile in St. Louis City

127 County.

129 Data Sources

130 COVID-19 and Chronic Disease Hospitalization Data

131 Data on COVID-19 and chronic condition hospitalizations were obtained from the

132 Hospital Industry Data Institute, a not-for-profit organization founded by the Missouri

133 Hospital Association that summarizes state level discharge data. The COVID-19 data

134 provided information on the numbers of COVID-19 discharges by patient ZCTA and by

135 age group from April 1, 2020 to September 30, 2020. In addition to the COVID-19

136 hospitalization data, data on the number of confirmed COVID-19 cases were obtained

137 from the county Departments of Health. COVID-19 case data were included as one of

138 the potential predictors of COVID-19 hospitalization risks. Data on chronic conditions

139 were extracted for the time period 2019-2020 based on ICD-10 codes and included the 
140 following conditions/behaviors: obesity, tobacco use, cancer (breast, colorectal,

141 prostate, lung, endometrial, leukemia and lymphoma), chronic obstructive pulmonary

142 disease, chronic kidney disease, heart failure, and diabetes. These conditions were

143 selected due to their potential association with COVID-19 severity. All data were

144 aggregated to the ZCTA-level to facilitate subsequent ZCTA-level analyses. The ZCTA-

145 level risks of these conditions were then computed and presented as disease-specific

146 hospitalizations per 100 population.

Socioeconomic, demographic and base map data

ZCTA-level data on socioeconomic and demographic factors including age, sex, race,

151 population density, education level, and median income, were obtained from the U.S.

152 Census Bureau 2018 American Community Survey (ACS) 5-year estimates [15]. The

153 cartographic boundary files, used for generating maps, were obtained from the US

154 Census Bureau Website [16].

All descriptive analyses were performed in $\mathrm{R}$ version 4.1.0 [17] using RStudio version Shapiro-Wilk test. Medians as well as $1^{\text {st }}$ and $3^{\text {rd }}$ quartiles were used as measures of

162 normally distributed. The COVID-19 ZCTA-level hospitalization risks were directly age163 standardized, in STATA version 16 [19], using the 2010 US population as the standard 164 population. 


\section{Investigation of Predictors of COVID-19 Hospitalizations}

167 Global Models

168 Univariable global Poisson models were used to assess simple associations between 169 each of the potential predictors and COVID-19 hospitalization risk. As opposed to local 170 models that estimate as many regression coefficients per predictor as the number of 171 geographic units, global models assume constant relationships between each potential

172 predictor and the outcome and therefore estimate one regression coefficient per

173 potential predictor. These models were fit under the Generalized Linear Model (GLM)

174 framework in R [17] specifying log link. The dependent variable was the expected count

175 of COVID-19 hospitalizations in each ZCTA based on the age-adjusted/standardized

176 number of COVID-19 hospitalizations and the offset was the natural log of the

177 population in each ZCTA. A relaxed $\alpha$ of 0.15 was used to assess potentially significant 178 predictors in univariable models. The linearity of the relationships between the log risk 179 and potential predictor variables was assessed graphically.

181 Spearman rank correlation coefficients were computed to assess bivariate correlations 182 among the potential predictor variables identified during the univariable analyses using $183 \mathrm{R}$ [17]. Variables with correlation coefficients greater than 0.7 were considered highly 184 correlated. To avoid multicollinearity, only one of a pair of highly correlated variables 185 was retained for further assessments using multivariable Poisson model. Biological and 186 statistical considerations were used to determine which of a pair of highly correlated 187 variables to retain. Non-correlated variables that had univariable $p \leq 0.15$ were assessed 
188 in a multivariable global Poisson model, built using manual backwards elimination and an $\alpha$ of 0.05 . Variables were considered as confounders if their removal from the model resulted in changes of at least $20 \%$ of the coefficients of any of the variables in the

191 model. Confounders were retained in the final main effects model. Biologically plausible

192 two-way interactions between variables in the final main effects multivariable model

193 were assessed and the significant ones retained in the final model. The final Poisson 194 regression model was then assessed for overdispersion.

Due to the presence of overdispersion in the final Poisson model (based on comparison of model deviance and degrees of freedom), a global negative binomial model was built.

198 The process of building the negative binomial (NB) model was similar to that of the 199 Poisson model described above. However, the glm.nb function of the MASS package 200 [20] of R [17] was used instead of the glm function. The rest of the model specifications 201 were similar to the Poisson model. Goodness-of-fit of the final global NB model was 202 assessed using Pearson and Deviance chi-square goodness-of-fit tests.

\section{Local Models}

205 To assess if the association between each of the predictors and hospitalization risks 206 varied by geographic location, a geographically weighted negative binomial (GWNB)

207 model, proposed by Silva and Rodrigues [21], was fit to the data specifying the same 208 outcome, link function, offset and significant predictors as in the final global

209 multivariable NB model. However, unlike the global multivariable NB model that 210 estimates one regression coefficient for each predictor and thus assumes a constant 
211 strength of association across all ZCTAs, the GWNB theoretically estimates as many

212 regression coefficients as the number of ZCTAs. Essentially, GWNB evaluates a local

213 model of the outcome by fitting a regression equation to every ZCTA in the dataset.

214 These separate model equations are constructed by incorporating the outcome and

215 predictor variables of the ZCTAs that fall within the neighborhood of each target ZCTA.

216 Therefore, the GWNB allows identification of local variations in the strength of

217 associations and therefore giving the importance of specific predictors in different local

218 areas (ZCTAs). This implies that some factors may be more important predictors of

219 hospitalization risk in some ZCTAs than others.

221 The local GWNB model was fit in SAS version 9.4 [22] using a SAS/IML macro [23].

222 The estimation of local regression coefficients was based on biquadratic kernel

223 weighting function [23], while the bandwidth was estimated using the adaptive method

224 which allows the size of the bandwidth to vary based on the density of observations.

225 Bias-corrected Akaike Information Criteria (AICc) was used to determine the optimum

226 kernel bandwidth and for comparing the goodness-of-fit of the global NB and GWNB

227 models. The better fitting model was identified as the one with the lower AICc value.

229 Stationarity of the GWNB coefficients was assessed using: (a) randomization non-

230 stationarity test based on 999 replications [24]; (b) comparison of the interquartile range

231 of the local GWNB model coefficients with the standard error estimates of the global NB

232 model. Local coefficients whose interquartile ranges were larger than twice the standard 
medRxiv preprint doi: https://doi.org/10.1101/2021.10.21.21265289; this version posted October 25, 2021. The copyright holder for this preprint

(which was not certified by peer review) is the author/funder, who has granted medRxiv a license to display the preprint in perpetuity.

It is made available under a CC-BY 4.0 International license .

233 error of the regression coefficient from the global NB model were considered non-

234 stationary $[25,26]$.

235

\section{Cartographic Displays}

237 Choropleth maps showing the geographic distributions of ZCTA-level age-adjusted

238 COVID-19 hospitalization risks, the socioeconomic, demographic and chronic disease

239 factors as well as local regression coefficients from the GWNB models were generated

240 using QGIS 3.16.6 [27]. Jenk's optimization classification scheme [28-30] was used to

241 determine the critical intervals of the choropleth maps. 


\section{Results}

\section{Descriptive Statistics}

244 The ZCTA-level median percentage of males was $48.6 \%$ while that of black and

245 Hispanic populations were $3.7 \%$ and $2.2 \%$, respectively (Table 1). For education

246 variables, $38.2 \%$ of the population had high school education, $23 \%$ had some college

247 education while $8.6 \%$ had associate's degree and $18 \%$ had bachelor's degree. The

248 median household income was just over $\$ 59,400$ with $9.5 \%$ of the ZCTA-level

249 population living below the poverty line. Among chronic conditions investigated, Chronic

250 Kidney Disease had the highest hospitalization risk (7.6\%) followed by diabetes $(7.5 \%)$

251 and heart failure had the lowest (3.2\%) (Table 1). The ZCTA-level median number of

252 confirmed cases of COVID-19 was 360 cases which was equivalent to $2.2 \%$ of the

253 population at ZCTA-level (Table1).

\section{Predictors of COVID-19 Hospitalization Risks}

256 Global Model

257 A number of variables had univariable associations with COVID-19 hospitalization risks

258 at a relaxed $p<0.2$ (Table 2). Of the assessed demographic variables, only percentage

259 of black population had a univariable association $(p<0.001)$ with hospitalization risk. By

260 contrast, all the assessed educational, economic, health behavior and chronic disease

261 variables had significant univariable associations with COVID-19 hospitalization risks

262 (Table 2). The ZCTA-level risk of confirmed COVID-19 cases had a significant

$263(p<0.001)$ univariable association with COVID-19 hospitalization risk but the raw count

264 of COVID-19 cases per ZCTA did not $(p=0.9)($ Table 2$)$. 
266 Based on the final global multivariable NB model, the ZCTA-level hospitalization risks

267 were higher in ZCTAs that were high in the following predictors: percentage of black

268 population $(p=0.0416)$, percentage of population with some college education

$269(p=0.0005)$, percentage of individuals hospitalized with diabetes $(p<0.0001)$, and

270 number of ZCTA-level COVID-19 cases per 100 population $(p=0.0001)$ (Table 3). A

271 map of the distribution of age-adjusted COVID-19 hospitalization risks and each of the

272 significant predictors is shown in Figure 2. High age-adjusted COVID-19 hospitalization

273 risks tended to occur in the Northeast of the study area and included ZCTAs in parts of

274 St. Charles, St. Louis and Louis City counties. These areas also had high percentages

275 of black population, individuals with some college education, those with high diabetes

276 hospitalization risks as well as high risks of COVID-19 cases (Figure 2). High

277 hospitalization risks were also evident in the Southwest areas of the study area that

278 included parts of Warren and Franklin counties. It is worth noting that these areas also

279 tended to have high diabetes hospitalization risks and percentages of the population

280 with some college education (Figure 2). Since the global model did not show evidence

281 of good fit based on both Deviance $(p=0.03)$ and Pearson $(p=0.01)$ goodness-of-fit

282 tests, stationarity of the regression coefficients was assessed using a local GWNB

283 model. 
Local Model

285 The p-values of the stationarity tests from the GWNB model indicate that the coefficients for the association between COVID-19 hospitalization risks and percentage

287 of black population $(p=0.001)$ and number of hospitalized patients with diabetes per 100 288 population $(p=0.032)$ were non-stationary (Table 4). Additionally, comparison of the $2892 \times$ SEs of the global coefficients and IQR of the local coefficients showed evidence of 290 non-stationarity of the coefficients of the above two predictors as well as the population 291 adjusted cases of COVID-19 (Table 4).

293 The spatial distribution of the local coefficients of the three predictors whose relationship 294 with COVID-19 hospitalizations were identified as non-stationary provides visual 295 evidence for variability of the local relationships (Figure 3). Thus, associations of

296 COVID-19 hospitalization risks with percentage of black population, diabetes

297 hospitalization risks and COVID-19 adjusted cases varied considerably across the study 298 area, with a strong East-West gradient. The association between percentage of black 299 population and COVID-19 hospitalization risks, for instance, was positive in the 300 Northeast and negative in the West and Southwest. Moreover, the strength of the 301 association was higher in ZCTAs in the West compared to those near the center of the 302 study area. The strength of association between COVID-19 hospitalization risks with 303 diabetes hospitalization risks was also higher in the Northeast and lower in the West. All 304 ZCTAs, except one (63025), showed evidence of positive association between COVID-

30519 hospitalization risks and diabetes hospitalization risks. Finally, the association 306 between COVID-19 hospitalization and population adjusted cases of COVID-19 
medRxiv preprint doi: https://doi.org/10.1101/2021.10.21.21265289; this version posted October 25, 2021. The copyright holder for this preprint (which was not certified by peer review) is the author/funder, who has granted medRxiv a license to display the preprint in perpetuity.

It is made available under a CC-BY 4.0 International license.

307 increased from West to East, with the association staying positive in all ZCTAs of the

308 study area. It is worth noting that the local GWNB model had a much better goodness-

309 of-fit $(\mathrm{AlCc}=986.4)$ than the global model $(\mathrm{AICc}=1002.7)$. 


\section{Discussion}

311 The goal of this study was to investigate geographic disparities and identify predictors of

312 ZCTA-level COVID-19 hospitalization risks in the St. Louis area. The findings of this

313 study can be used to identify areas where the population is at higher risk of

314 hospitalization due to COVID-19 in order to guide planning and control efforts and to

315 reduce potential overburdening of hospitals during COVID-19 surges.

317 There was evidence of geographic disparities in COVID-19 age-adjusted hospitalization 318 risks in the study area. Urban ZCTAs in St. Louis City and St. Louis County exhibited 319 high hospitalization risks. These ZCTAs also have high percentages of the population 320 that are black, some as high as $98.4 \%$. Some of these ZCTA also had high diabetes 321 hospitalization risks. It is worth noting that some rural ZCTAs in Franklin and Warren

322 counties had high COVID-19 hospitalization risk but very low percentages of the 323 population that were black. However, these ZCTAs had high diabetes hospitalization

324 risks implying that the COVID hospitalization risks in these rural ZCTAs was more 325 driven by diabetes burden than demographic factors. Thus, although COVID-19 326 hospitalization risks in the more urban areas seems to be driven by the demographic

327 composition of the population, the risks in the more rural areas seem to be driven more 328 by diabetes burden. Geographic areas with intermediate to high COVID-19

329 hospitalization risks tended to have high percentages of the population with some 330 college education and included ZCTAs in Franklin, Jefferson, St. Louis City and St.

331 Louis County. It is worth noting that St. Louis City and St. Louis County tend to have 332 similar restrictions, but often time, the restrictions from the other counties are more 
333 laxed. Previous ecological and individual level studies have not considered education

334 level as a predictor of hospitalization risk. The level of education may be a proxy of

335 occupation and other sociodemographic factors that may impact both the risk of

336 infection and the resulting severity of the disease and hence hospitalization risks.

338 The above findings are consistent with those from previous ecological studies that

339 investigated risk factors and predictors of COVID-19 hospitalization. For instance, an

340 ecological study by Nguyen et al. reported that diabetes was a significant predictor of

341 increased COVID-19 hospitalization risk at the county level in Georgia, USA even after

342 controlling for sociodemographic and economic factors [31]. On the contrary, an Iranian

343 study conducted at the provincial level did not find a significant association when only

344 controlling for chronic disease factors [32]. This may indicate differences of relationships

345 in different geographic areas and populations as well as the importance of controlling for

346 sociodemographic factors when evaluating the impact of chronic disease variables on

347 COVID-19 hospitalization risk. Considering the fact that ZCTAs with high diabetes

348 hospitalization risks also tended to have high COVID-19 hospitalization risks, COVID-19

349 mitigation efforts may need to be targeted to these ZCTAs to reduce the potential

350 burden of the disease.

352 Interestingly, the study by Nguyen et al., which also considered sociodemographic and

353 economic factors as well as comorbidities, did not find a significant association between

354 percentage of black population with COVID-19 hospitalization risk [31]. However, it did

355 identify other socioeconomic factors that this study did not consider, including: 
medRxiv preprint doi: https://doi.org/10.1101/2021.10.21.21265289; this version posted October 25, 2021. The copyright holder for this preprint (which was not certified by peer review) is the author/funder, who has granted medRxiv a license to display the preprint in perpetuity.

It is made available under a CC-BY 4.0 International license.

356 percentage of children in poverty and percentage of the population with severe housing

357 problems. Although not directly comparable with the current ecological study, previous

358 individual level studies have also identified associations between black race and

359 COVID-19 hospitalization risk [8, 13, 33].

360

361 The local GWNB model allowed modeling of geographically varying associations

362 between COVID-19 hospitalization risks and its predictors instead of assuming constant

363 associations across the study area. Although the coefficients of percentage of black

364 population, diabetes hospitalization risk and risk of COVID-19 infections varied spatially,

365 the coefficients of percentage of the population with some college education did not and

366 hence was modeled as stationary. This suggests that the coefficients for the percentage

367 of the population with some college education are generalizable to all ZCTAs in the

368 study area. In contrast, geographic variations in the associations between COVID-19

369 hospitalization risks and the percentage of black population, diabetes hospitalization

370 risks and risks of COVID-19 infections suggest that global coefficients do not

371 adequately describe the associations between COVID-19 hospitalization risks and these

372 predictors across the study area. These findings have health planning and service

373 provision implications. For instance, a "one size fits all" approach would not be suitable

374 for addressing geographic disparities in COVID-19 hospitalization risks across the study

375 area since some predictors are more important in some locales than others. Thus,

376 different locales may require slightly different strategies depending on the most

377 important predictors driving COVID-19 hospitalization risk in the location. Therefore,

378 planning for hospital capacity and other disease management and control efforts will 
379 need to use evidence-based approaches informed by empirical evidence from both 380 global and local models.

\section{Strengths and limitations}

383 This study used both global and local models to investigate geographic disparities and

384 identify predictors of COVID-19 hospitalization risks in St. Louis region of Missouri. The use of local models to investigate stationarity of regression coefficients of significant predictors and model non-stationary coefficients is a key strength of the study. This approach is particularly important in guiding local health planning since the importance of different predictors are not constant across the study area implying that different management and control strategies may need to be used in different areas. Therefore, modeling approaches that use both global and local models help to better understand

391 the relationships between the outcome and predictors and may be more useful in 392 guiding control efforts at the local level. However, the study is not without limitations.

393 The hospital data has limitations associated with diagnostic classifications of COVID-19 394 in situations when the patient has co-morbidities that may have contributed to 395 hospitalization. Additionally, there may be geographic differences in COVID-19 case 396 ascertainment and reporting.

\section{Conclusions}

399 There is evidence of geographic disparities in COVID-19 hospitalization risks in the St.

400 Louis area of Missouri. These disparities are driven by socioeconomic, demographic 401 and health-related factors. The impacts of these factors vary by geographical location 
medRxiv preprint doi: https://doi.org/10.1101/2021.10.21.21265289; this version posted October 25, 2021. The copyright holder for this preprint (which was not certified by peer review) is the author/funder, who has granted medRxiv a license to display the preprint in perpetuity.

It is made available under a CC-BY 4.0 International license .

402 with some factors being more important predictors of COVID-19 hospitalization risk in

403 some locales than others. This demonstrates the importance of using not only global but

404 also local models to investigate determinants of geographic disparities in health

405 outcomes and utilization of health services. This study's findings are useful for informing

406 healthcare system planning to identify geographic areas likely to have high numbers of

407 individuals needing hospitalization as well as in guiding vaccination efforts.

408 


\section{Declarations}

\section{Ethical approval and consent to participate}

411 The study was approved by the North Carolina State University Institutional Review

412 Board (IRB number: 22342) and all study methods were carried out in accordance with

413 relevant guidelines and regulations. The study used anonymized secondary data

414 provided to the investigators, by the Hospital Industry Data Institute, in such a manner

415 that the identify of human subjects cannot be ascertained directly or through identifiers

416 linked to the subjects. The investigators did not contact the subjects and did not re-

417 identify subjects.

419 Consent for publication

420 Not applicable.

421

422 Availability of data and materials

423 The investigators cannot share the datasets, which are not publicly available, because

424 they do not have legal ownership nor authority to share the data. However, the data are

425 available upon request from the Hospital Industry Data Institute at 4712 Country Club

426 Drive P.O. Box 60 Jefferson City, MO 65102-0060, telephone (573)893-3700.

\section{Competing interests}

429 The authors declare that they have no competing interests. 


\section{Funding}

433 This work was supported by CDC U01CK000587-01M001. The funders had no role in

434 study design, data collection and analysis, decision to publish, or preparation of the

435 manuscript.

436

\section{Authors' contributions}

$438 \mathrm{SL}, \mathrm{ALL}, \mathrm{CL}$, and $\mathrm{AO}$ conceptualized research idea

439 LL, DT collected and curated the data

$440 \mathrm{MI}, \mathrm{PD}, \mathrm{SL}, \mathrm{ALL}, \mathrm{CL}$ and $\mathrm{AO}$ analyzed data

$441 \mathrm{MI}, \mathrm{PD}$ and $\mathrm{AO}$ wrote the manuscript

442 All authors edited the manuscript

443 All authors read and approved the final manuscript.

\section{Acknowledgements}

446 We thank the St. Louis Comparative Modeling Network for facilitating access to data 447 and useful discussions. 
medRxiv preprint doi: https://doi.org/10.1101/2021.10.21.21265289; this version posted October 25, 2021. The copyright holder for this preprint (which was not certified by peer review) is the author/funder, who has granted medRxiv a license to display the preprint in perpetuity.

It is made available under a CC-BY 4.0 International license .

\section{References}

1. World Health Organization (WHO). WHO Coronavirus (COVID-19) Dashboard. Accessed on July 8, 2021. https://covid19.who.int/. WHO. 2021.

2. Keene AB, Shiloh AL, Eisen L, Berger J, Karwa M, Fein D, et al. Critical Care Surge During the COVID-19 Pandemic: Implementation and Feedback From Frontline Providers.

3. Hassan EM, Mahmoud HN. Impact of multiple waves of COVID-19 on healthcare networks in the United States. PLoS One. 2021;16 3 March.

4. Khera R, Jain S, Lin Z, Ross JS, Krumholz HM. Evaluation of the anticipated burden of COVID-19 on hospital-based healthcare services across the United States. medRxiv. 2020.

5. Ghanchi H, Takayanagi A, Savla P, Hariri OR, Tayag EC, Schiraldi M, et al. Effects of the COVID-19 Pandemic on Stroke Patients. Cureus. 2020.

6. Garg S, Kim L, Whitaker M, Cummings C, Holstein R, Prill M, et al. MMWR Hospitalization Rates and Characteristics of Patients Hospitalized with LaboratoryConfirmed Coronavirus Disease 2019 - COVID-NET, 14 States, March 1-30, 2020. 2019.

\section{CDC COVID-19 Response Team. Severe Outcomes Among Patients with}

Coronavirus Disease 2019 (COVID-19) — United States, February 12-March 16, 2020. Morb Mortal Wkly Rep. 2020;69:343-6. https://www.cdc.

8. Gao Y dong, Ding M, Dong X, Zhang J jin, Kursat Azkur A, Azkur D, et al. Risk factors for severe and critically ill COVID-19 patients: A review. Allergy: European Journal of Allergy and Clinical Immunology. 2020;76:428-55.

9. Huang C, Wang Y, Li X, Ren L, Zhao J, Hu Y, et al. Clinical features of patients infected with 2019 novel coronavirus in Wuhan, China. Lancet. 2020;395:497-506.

10. Fadl N, Ali E, Salem TZ. COVID-19: Risk Factors Associated with Infectivity and Severity. Scand J Immunol. 2021;:e13039.

11. Prevention C for DC and. COVID-19 Racial and Ethnic Health Disparities | CDC. Centers for Disease Control and Prevention. 2021. https://www.cdc.gov/coronavirus/2019-ncov/community/health-equity/racial-ethnicdisparities/disparities-hospitalization.html\#print. Accessed 30 Jun 2021.

12. Zhou Y, Chi J, Lv W, Wang Y. Obesity and diabetes as high-risk factors for severe coronavirus disease 2019 (Covid-19). Diabetes/Metabolism Research and Reviews. 2020;37.

13. Harlem G. Descriptive analysis of social determinant factors in urban communities affected by COVID-19. J Public Heal (United Kingdom). 2020;42:466-9.

14. Robilotti E V., Babady NE, Mead PA, Rolling T, Perez-Johnston R, Bernardes M, et al. Determinants of COVID-19 disease severity in patients with cancer. Nat Med. 
medRxiv preprint doi: https://doi.org/10.1101/2021.10.21.21265289; this version posted October 25, 2021. The copyright holder for this preprint (which was not certified by peer review) is the author/funder, who has granted medRxiv a license to display the preprint in perpetuity.

It is made available under a CC-BY 4.0 International license .

2020;26:1218-23.

15. US Census Bureau. ACS Demographic and Housing Estimates, 2018: 5-Year Estimates. 2018. https://www.census.gov/programs-surveys/acs. Accessed 30 Jan 2020.

16. United States Census Bureau. TIGER/Line Shapefiles. 2019.

https://www.census.gov/geographies/mapping-files/time-series/geo/tiger-geodatabasefile.html. Accessed 1 Dec 2019.

17. $R$ Core Team. R: A language and environment for statistical computing. $R$ Foundation for Statistical Computing, Vienna, Austria. URL https://www.R-project.org/. 2021. https://www.r-project.org/.

18. RStudio Team. RStudio: Integrated Development for R. RStudio, PBC, Boston, MA URL http://www.rstudio.com/. 2021.

19. StataCorp. Stata Statistical Software: Release 16. College Station, TX: StataCorp LLC. 2019.

20. W. N. Venables; B. D. Ripley. Modern Applied Statistics with S. Fourth. New York: Springer; 2002. https://www.stats.ox.ac.uk/pub/MASS4/.

21. da Silva AR, Rodrigues TCV. Geographically Weighted Negative Binomial Regression-incorporating overdispersion. Stat Comput. 2014;24:769-83.

22. SAS Institute. Statistical Analysis System (SAS) Version 9.4. Cary, NC, USA. SAS Institute Inc. 2016.

23. Ricardo Da Silva A. A SAS $®$ Macro for Geographically Weighted Negative Binomial Regression.

24. Hope ACA. A Simplified Monte Carlo Significance Test Procedure on JSTOR. J R Stat Soc Ser B Stat Methodol. 1968;30:582-598. https://www.jstor.org/stable/2984263?seq=1. Accessed 27 May 2021.

25. Brunsdon C, Fotheringham AS, Charlton ME. Geographically weighted regression: a method for exploring spatial nonstationarity. Geogr Anal. 1996;28:281-98. doi:10.1111/j.1538-4632.1996.tb00936.x.

26. Fotheringham AS, Brunsdon C, Charlton M. Geographically Weighted Regression: The Analysis of Spatially Varying Relationships. West Sussex, England: John Wiley \& Sons Ltd; 2002.

27. QGIS.org. QGIS Geographic Information System. 2021. http://www.qgis.org.

28. AD Cliff; P Haggett. Atlas of Disease Distributions: Analytic Approaches to Epidemiological Data. Oxford, United Kingdom: Basil Blackwell Ltd; 1988.

29. Jenks GF. The Data Model Concept in Statistical Mapping. Int Yearb Cartogr. 1967;7:186-90.

30. McMaster R. In Memoriam: George F. Jenks (1916-1996). Cartogr Geogr Inf Sci. 
526 31. Nguyen TH, Shah GH, Schwind JS, Richmond HL. Community Characteristics and 527 COVID-19 Outcomes: A Study of 159 Counties in Georgia, United States. J Public Heal 528 Manag Pract. 2021;27:251-7.

529 32. Khorrami Z, Nili S, Sharifi H, Eybpoosh S, Shokoohi M. Association of cigarette 530 smoking, obesity, and underlying medical conditions with COVID-19 hospitalization and 531 mortality in Iran: A nationwide retrospective ecological study. Med J Islam Repub Iran. 532 2020;34:133.

533 33. Ko JY, Danielson ML, Town M, Derado G, Greenlund KJ, Daily Kirley P, et al. Risk 534 Factors for COVID-19-associated hospitalization: COVID-19-Associated Hospitalization 535 Surveillance Network and Behavioral Risk Factor Surveillance System. 
$\underline{\text { Tables }}$

Table 1: Descriptive Statistics of ZCTA-level Potential Predictors of COVID-19 Hospitalization Risks in the St. Louis Area, Missouri

\begin{tabular}{|c|c|c|c|c|}
\hline Type of Variable & Variable & Median & $\begin{array}{c}\text { First } \\
\text { Quartile }\end{array}$ & $\begin{array}{c}\text { Third } \\
\text { Quartile }\end{array}$ \\
\hline \multicolumn{5}{|l|}{ Demographic Factors } \\
\hline & $\%$ male population & 48.6 & 47.4 & 50.3 \\
\hline & $\%$ black population & 3.7 & 0.9 & 34.2 \\
\hline & \% Hispanic/Latino population & 2.2 & 1.0 & 3.2 \\
\hline \multicolumn{5}{|l|}{ Educational Variables } \\
\hline & $\%$ with $\leq$ high school education & 38.2 & 23.9 & 47.6 \\
\hline & $\%$ with some college & 23.0 & 19.8 & 25.6 \\
\hline & $\%$ with associate's degree & 8.6 & 6.6 & 10.6 \\
\hline & \% with bachelor's degree & 18.0 & 9.4 & 25.9 \\
\hline \multicolumn{5}{|l|}{ Economic Variables } \\
\hline & \% below poverty level & 9.5 & 5.8 & 16.8 \\
\hline & median household income & $59,768.5$ & 46005.3 & 77504.0 \\
\hline \multicolumn{5}{|c|}{ Health Behavior (ZCTA-level number of hospitalized patients that use tobacco per 100} \\
\hline & $\%$ tobacco 1 & 10.4 & 6.8 & 14.5 \\
\hline \multicolumn{5}{|c|}{ Co-morbidities (ZCTA-level number of hospitalized patients with specific condition per 100} \\
\hline & $\%$ obesity & 7.0 & 5.6 & 8.0 \\
\hline & $\%$ diabetes & 7.5 & 6.5 & 9.2 \\
\hline & $\%$ cancer & 3.8 & 3.3 & 4.3 \\
\hline & $\%$ COPD $^{2}$ & 4.0 & 3.1 & 4.9 \\
\hline & $\% \mathrm{CKD}^{3}$ & 7.6 & 6.4 & 8.9 \\
\hline & $\%$ heart failure & 3.2 & 2.6 & 3.8 \\
\hline \multicolumn{5}{|l|}{ COVID-19 Cases } \\
\hline & total cases & 360 & 118 & 607 \\
\hline & cases per 100 population & 2.2 & 1.9 & 2.5 \\
\hline
\end{tabular}

542 1ZCTA-level \% of COVID-19 hospitalized patients that were tobacco users

$543{ }^{2}$ Chronic Obstructive Pulmonary Disease

$544{ }^{3}$ Chronic Kidney Disease 
546 Table 2: Univariable Associations of Sociodemographic, Economic, and Chronic 547 Disease Potential Predictors of COVID-19 Hospitalization Risk in the St. Louis

548 Area, Missouri

\begin{tabular}{|c|c|c|c|c|}
\hline Type of Variable & Variable & Coefficient & $\begin{array}{c}95 \% \text { Confidence } \\
\text { Interval }\end{array}$ & P-values \\
\hline \multicolumn{5}{|c|}{ Demographic Factors } \\
\hline & $\%$ black population & 0.007 & $0.005,0.009$ & $<0.0001$ \\
\hline & \% Hispanic/Latino population & -0.021 & $-0.056,0.016$ & 0.292 \\
\hline & $\%$ with $\leq$ high school education & 0.015 & $0.010,0.020$ & $<0.0001$ \\
\hline & $\%$ with some college education & 0.035 & $0.022,0.049$ & $<0.0001$ \\
\hline & $\%$ with associate's degree & 0.028 & $0.0002,0.055$ & 0.036 \\
\hline & $\%$ with bachelor's degree & -0.021 & $-0.028,-0.014$ & $<0.0001$ \\
\hline \multicolumn{5}{|c|}{ Health Behavior (ZCTA-level number of hospitalized patients that use tobacco per 100 Population) } \\
\hline & $\%$ tobacco $^{1}$ & 0.046 & $0.034,0.058$ & $<0.0001$ \\
\hline \multicolumn{5}{|c|}{ Co-morbidities (ZCTA-level number of hospitalized patients with specific condition per 100 Population) } \\
\hline & $\%$ obesity & 0.138 & $0.104,0.171$ & $<0.0001$ \\
\hline & $\%$ cancer & -0.029 & $-0.096,0.032$ & 0.377 \\
\hline & $\%$ COPD $^{2}$ & 0.11 & $0.055,0.164$ & $<0.0001$ \\
\hline & $\% \mathrm{CKD}^{3}$ & 0.1 & $0.068,0.131$ & $<0.0001$ \\
\hline
\end{tabular}

549 1ZCTA-level \% of COVID-19 hospitalized patients that were tobacco users

$550 \quad{ }^{2}$ Chronic Obstructive Pulmonary Disease

$551{ }^{3}$ Chronic Kidney Disease 
medRxiv preprint doi: https://doi.org/10.1101/2021.10.21.21265289; this version posted October 25, 2021. The copyright holder for this preprint (which was not certified by peer review) is the author/funder, who has granted medRxiv a license to display the preprint in perpetuity.

It is made available under a CC-BY 4.0 International license.

553 Table 3: Final Global Negative Binomial Model Showing Significant Determinants 554 of COVID-19 Hospitalization Risk in the St. Louis area

\begin{tabular}{lccc}
\hline \multicolumn{1}{c}{ Name } & Coefficient & $\begin{array}{c}\text { 95 \% Confidence } \\
\text { Interval }\end{array}$ & p-value \\
\hline \% black population & 0.0014 & $0.0001,0.0027$ & 0.0416 \\
$\%$ with some college education & 0.0180 & $0.0078,0.0281$ & 0.0005 \\
\% diabetes & 0.0628 & $0.0397,0.0860$ & $<0.0001$ \\
Confirmed COVID-19 cases & 0.2623 & $0.2027,0.3218$ & $<0.0001$ \\
per 100 population & & & \\
\hline
\end{tabular}

$555 \quad{ }^{1}$ Number of hospitalized patients with diabetes per 100 Population 
557 Table 4: Results of assessment of stationarity of the coefficients of the predictors of the COVID-19 hospitalization

558 risks in the St. Louis Area, Missouri

\begin{tabular}{lcccccc}
\hline & $\begin{array}{c}\text { Global } \\
\text { SE}^{1}\end{array}$ & $\begin{array}{c}\text { Global } \\
\text { SE}^{1} \mathbf{x}\end{array}$ & $\begin{array}{c}\text { IQR }^{2} \text { of Local } \\
\text { Coefficient }\end{array}$ & IQR-2(SE) & $\begin{array}{c}\text { Stationarity } \\
\text { test p-value }\end{array}$ & $\begin{array}{c}\text { Is Coefficient } \\
\text { Stationary? }\end{array}$ \\
\hline \% Black Population & 0.0007 & 0.0014 & 0.0148676 & 0.0134676 & 0.001 & $\mathrm{No}^{4}$ \\
\% With Some College Education & 0.0052 & 0.0104 & 0.0092401 & -0.0011599 & 0.406 & Yes \\
\% diabetes & 0.0118 & 0.0236 & 0.0416903 & 0.0180903 & 0.032 & $\mathrm{No}^{4}$ \\
Cases of COVID-19 per 100 population & 0.0304 & 0.0608 & 0.1164299 & 0.0556299 & 0.109 & $\mathrm{No}^{5}$ \\
\hline 1Standard Error & & & & & &
\end{tabular}

$559 \quad$ TStandard Error

$560 \quad$ Interqurtile Range

5613 Number of hospitalized patients with diabetes per 100 Population

$562{ }^{4}$ Coefficients are non-stationary based on both the p-value of the stationarity test and IQR-2(SE) assessment

$563{ }^{5}$ Coefficient is non-stationary based on IQR-2(SE) assessment 
medRxiv preprint doi: https://doi.org/10.1101/2021.10.21.21265289; this version posted October 25, 2021. The copyright holder for this preprint (which was not certified by peer review) is the author/funder, who has granted medRxiv a license to display the preprint in perpetuity.

\section{Figure Titles}

Figure 1: Map of study area showing geographic distribution of Zip Code Tabulation Areas and Counties

Figure 2: Geographic distribution of ZCTA-level COVID-19 age-adjusted hospitalization risks and its significant predictors in the St. Louis area, Missouri. 


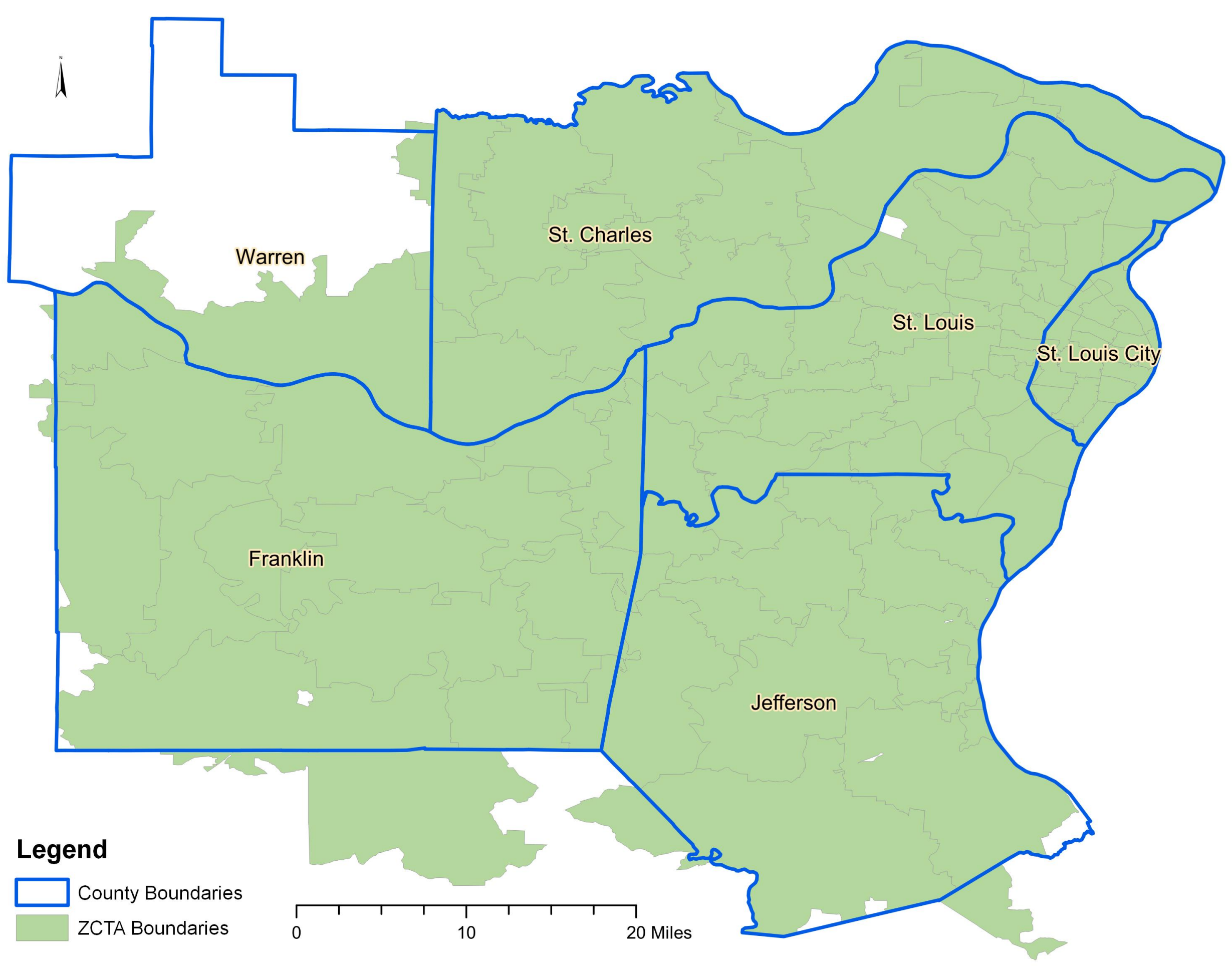




\section{$N \quad$ Counties in Study Area \\ Age-adjusted Hospitalizations Risks (Per 100 Population)}

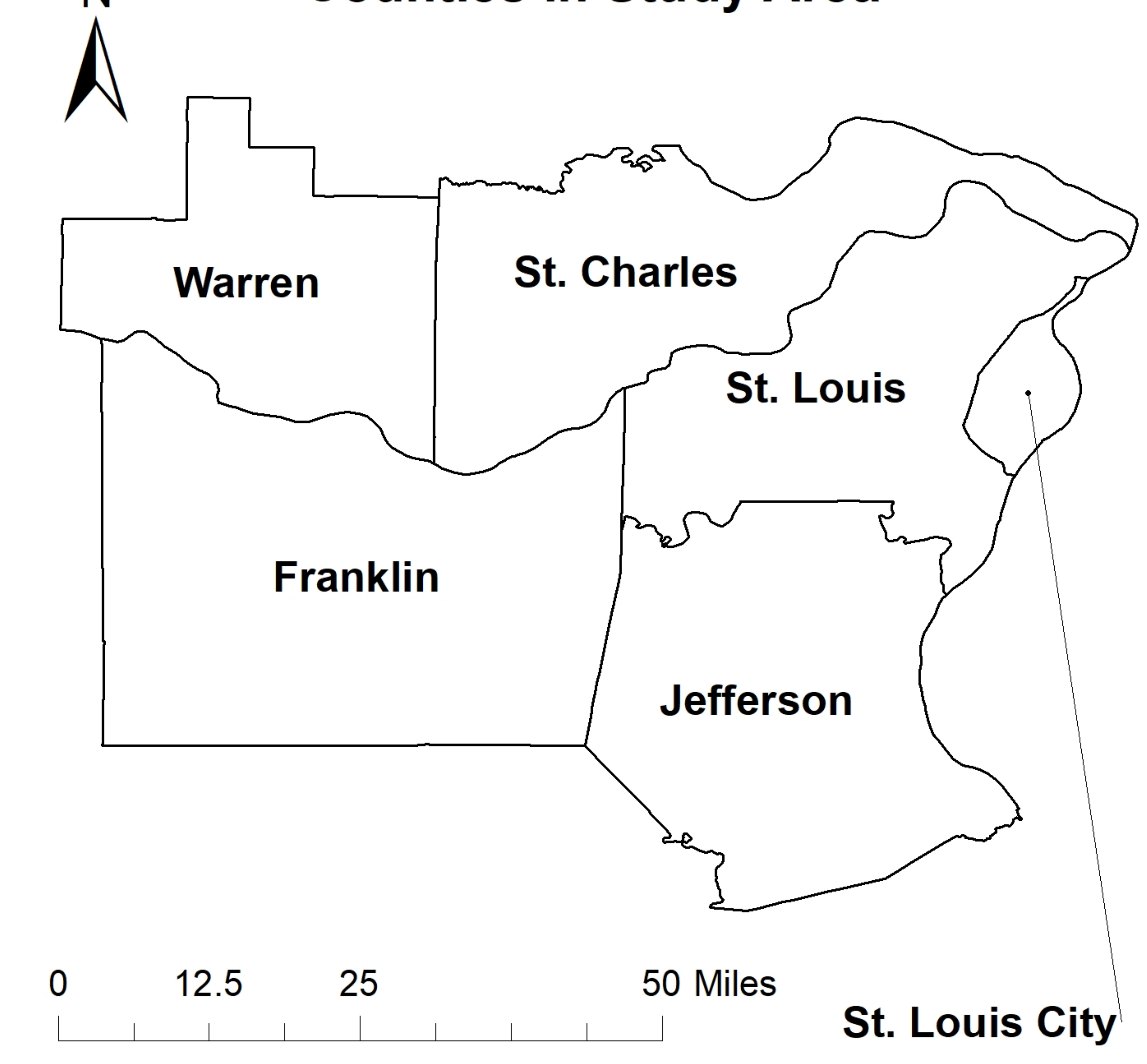

\% With Some College Education

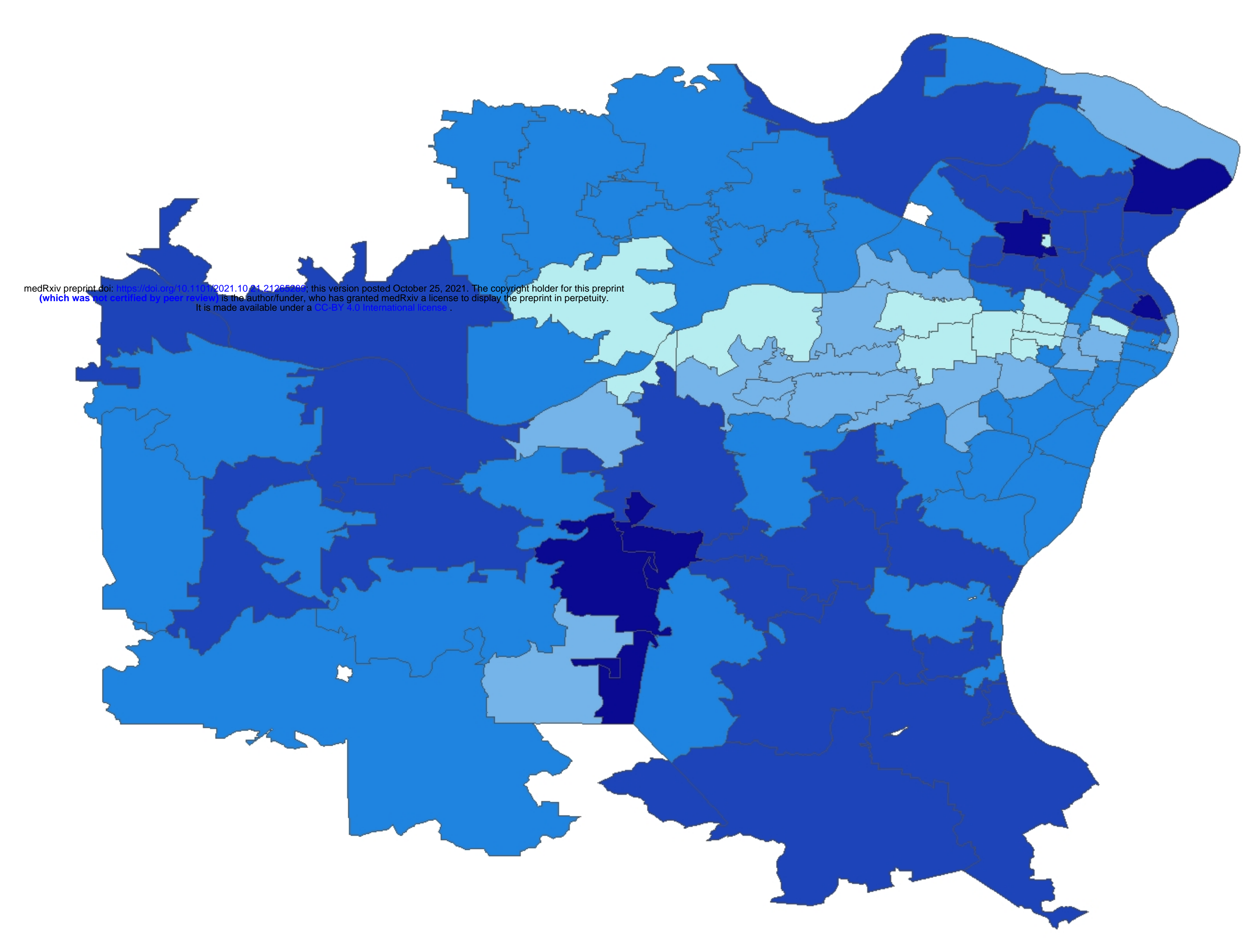

6.00 - $14.60 \square 19.81-24.40 \square 29.51$ - 37.10 - $14.61-19.80 \square 24.41-29.50$

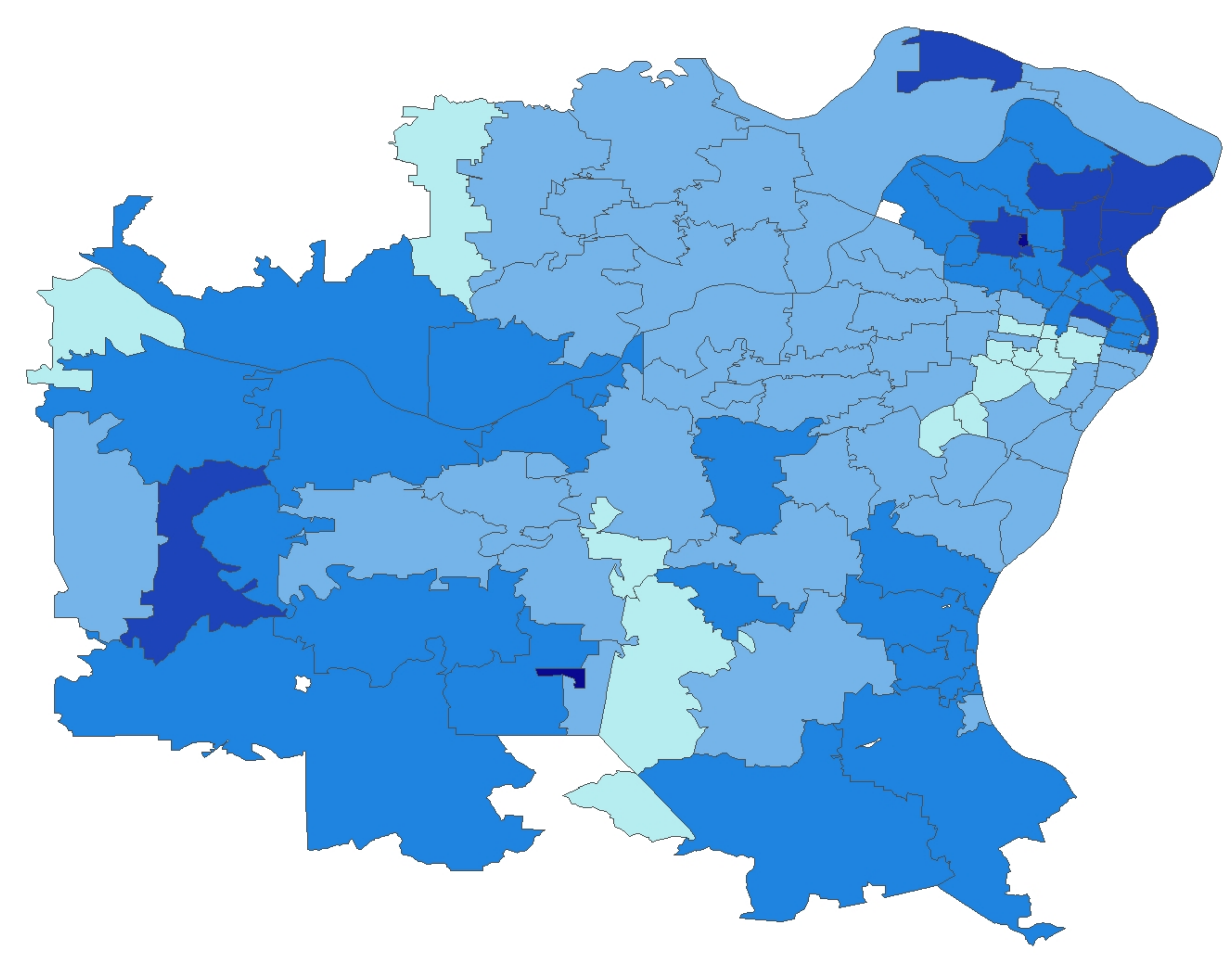

$0.18-0.59$

$0.98-1.54$

$0.60-0.97$

$1.55-2.44$

\section{Diabetes Hospitalization Risks} per 100 Population

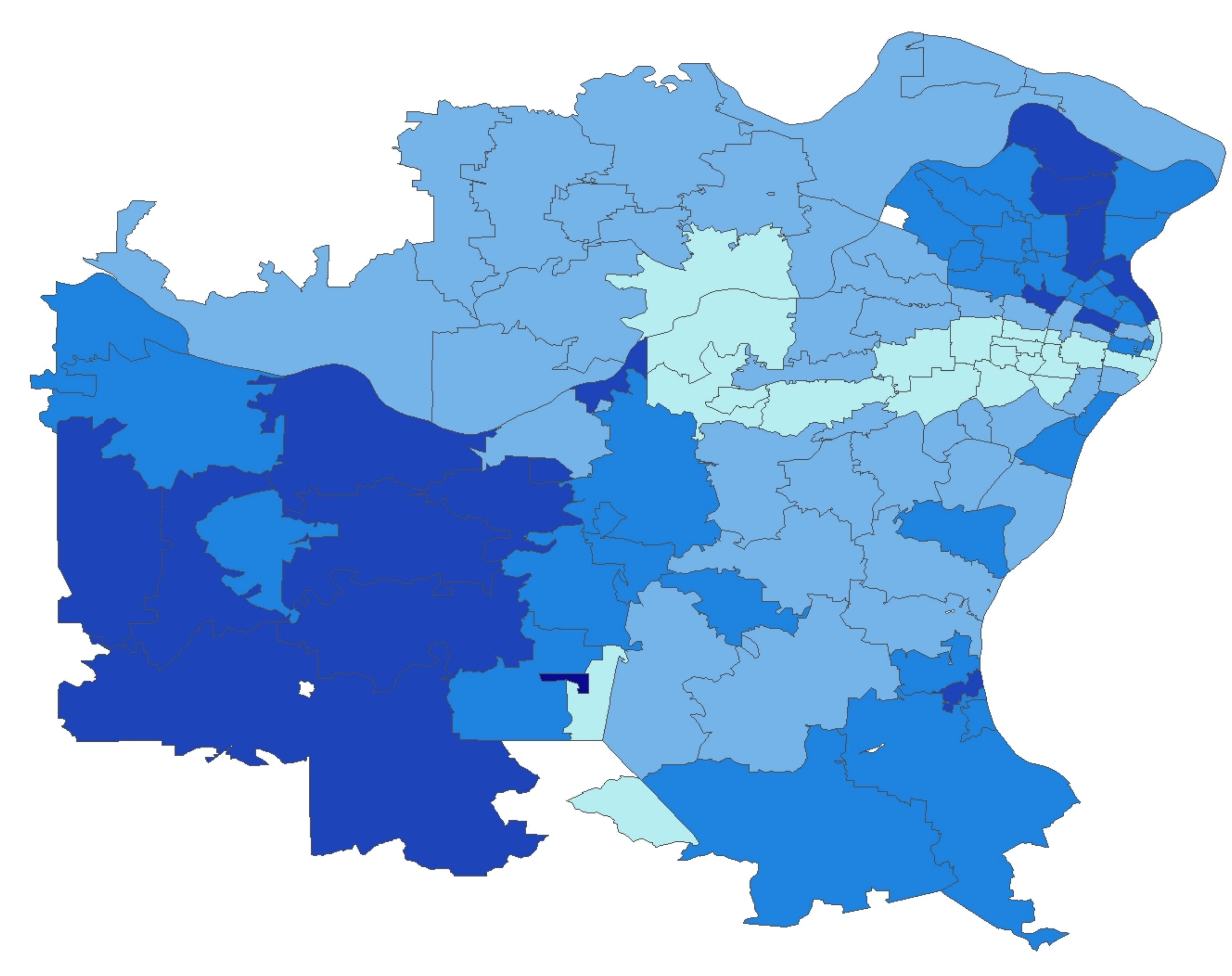

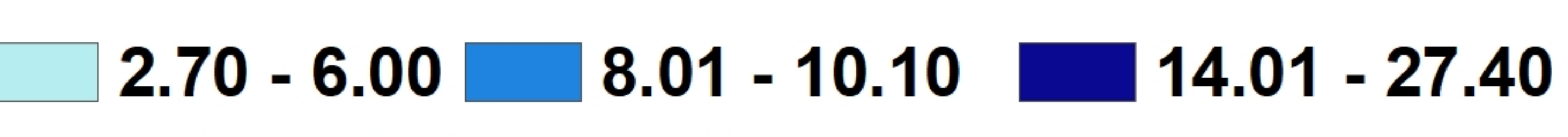

$6.01-8.00 \square 10.11-14.00$

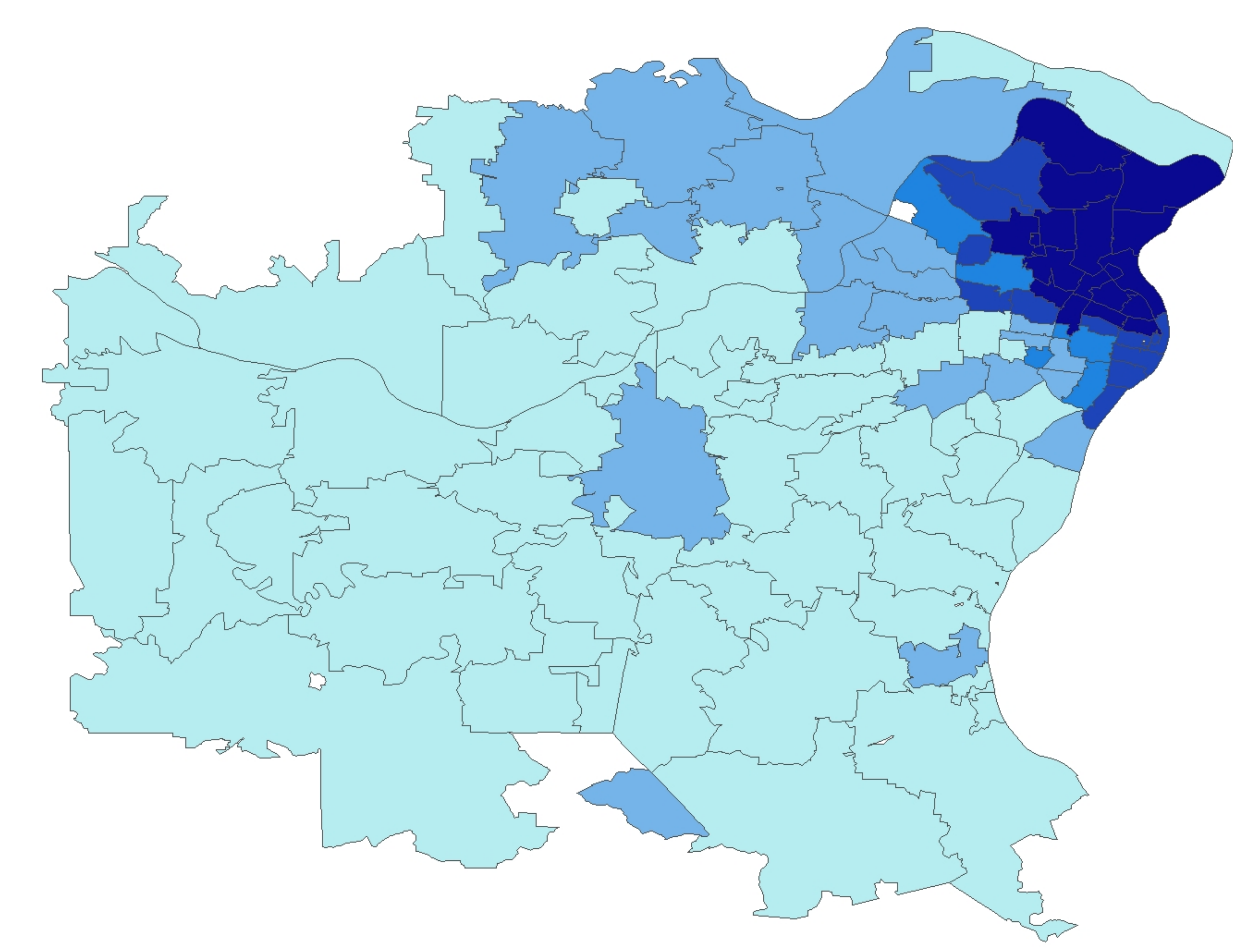

$0.00-3.30$ $12.81-31.00$ $31.01-53.10$

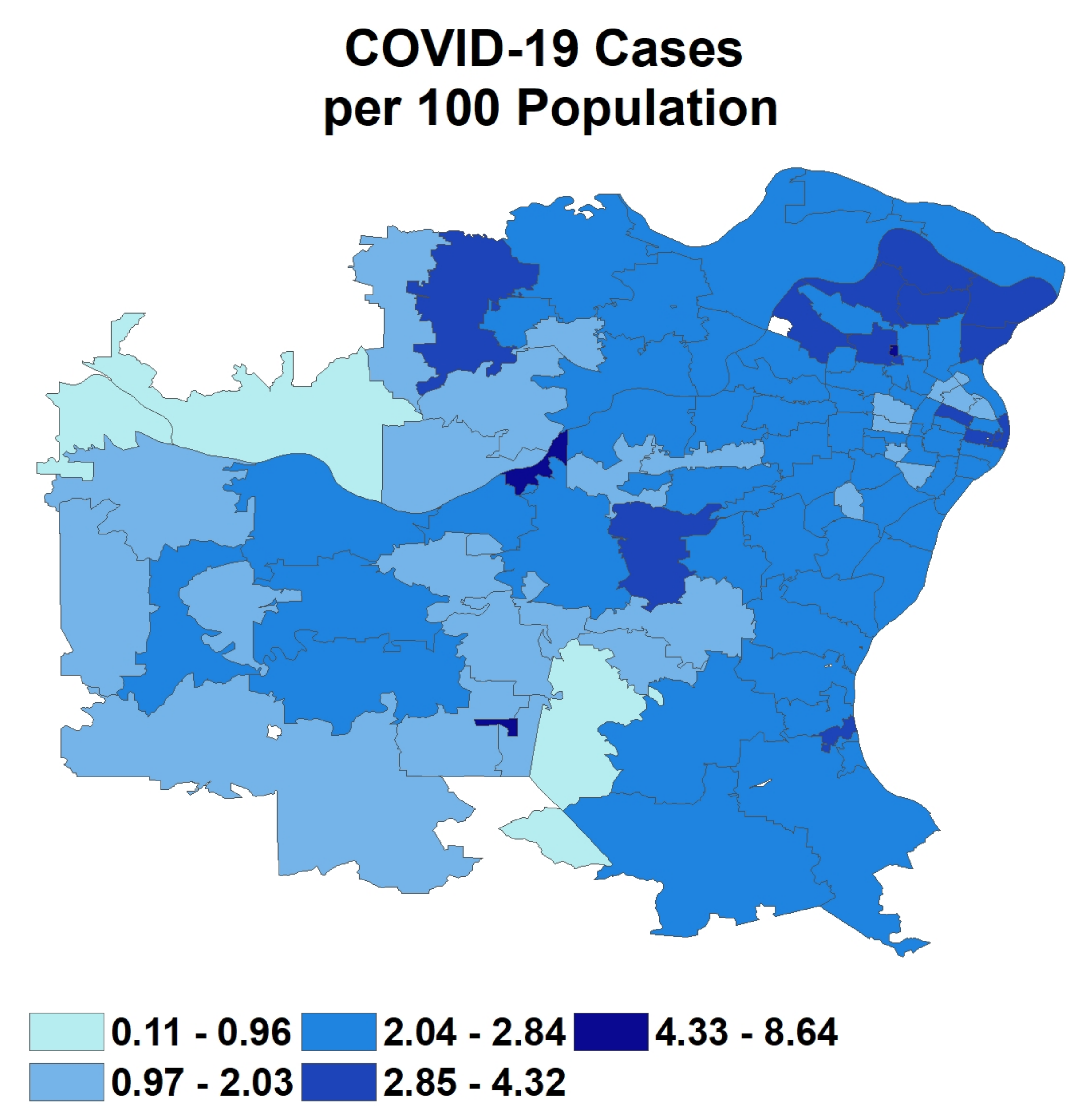

Source: U. S. Census Bureau, 2018 ACS; COVID Case Data from MO Depts, of Health; COVID Hosp. Data from Missouri Hospital Association 


\section{$\%$ Black Population Coefficient \\ \% Diabetes Hospitalization Coefficient}

CovID-19 Cases per 100

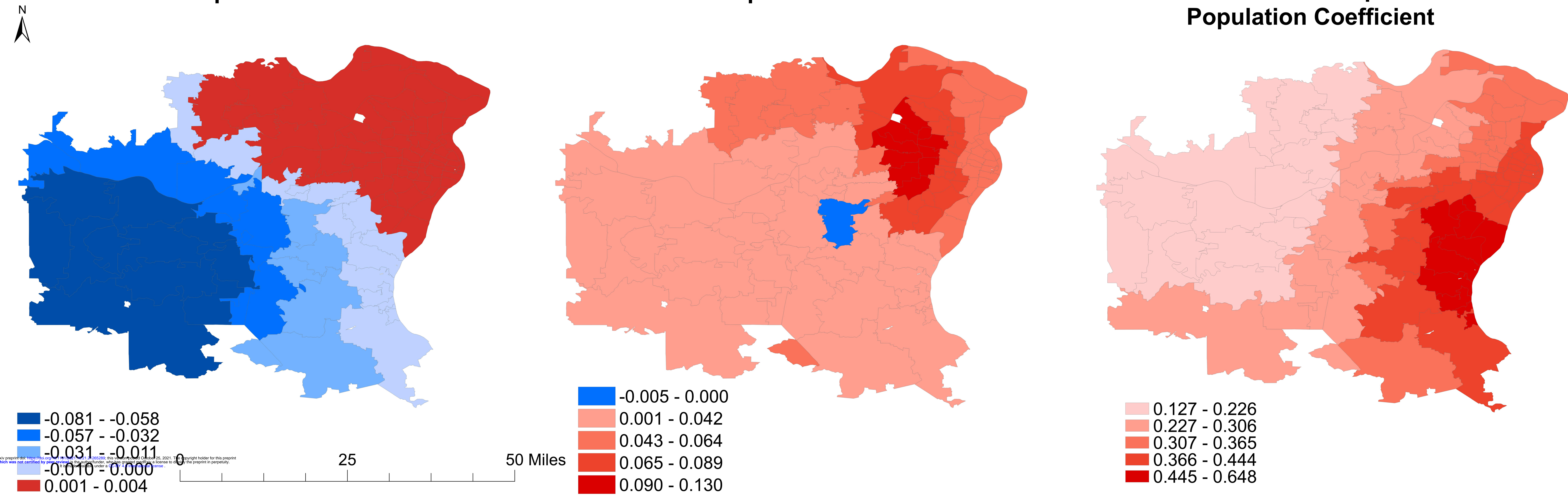

Source: U. S. Census Bureau, 2018 ACS; COVID Case Data from MO Depts, of Health; COVID Hosp. Data from Missouri Hospital Association 